\title{
An application of the theory of island biogeography to fish speciation on seamounts
}

\author{
Paul J. B. Hart*, Emma Pearson \\ Department of Biology, University of Leicester, Leicester LE1 7RH, UK
}

\begin{abstract}
Seamounts can be considered as islands in the deep. For many species, depth is just as much a barrier to dispersal as is the water between oceanic islands. This leads to the hypothesis that seamounts could be places where speciation readily occurs. Recent advances in the theory of island biogeography have allowed some detailed predictions about the degree of endemism and the diversity of species on oceanic islands. We have adapted this theory to seamounts, as underwater equivalents of islands. Three elements of this theory were tested as an illustration of what could be done, using published data on the diversity of reef-dwelling and benthic fish species found along the Hawaiian-Emperor seamount chain in the Pacific. Poor sampling makes it impossible at present to test the hypothesis that endemism is a humped function of seamount age. The data agrees with a further prediction that the total number of species is a humped function of seamount age. Finally, the prediction that fish diversity should be a function of seamount age and area is unsupported. We propose that the theory we have attempted to test could serve as a guide to what fish diversity might be expected from further sampling work.
\end{abstract}

KEY WORDS: Seamount · Island biogeography · Speciation $\cdot$ Hawaiian-Emperor Chain $\cdot$ Benthic and reef fish

Resale or republication not permitted without written consent of the publisher

\section{INTRODUCTION}

Documenting the existence and origin of biodiversity in the world's oceans is made difficult by the nature of the habitat. Despite this, the task cannot be neglected given that the oceans cover two-thirds of the world's surface and are the source of a significant amount of food produced for human consumption. We need to know what is in the sea and how diversity arises if management and conservation are to be effective. Steps in the right direction have been taken by the recently completed Census of Marine Life (http:// www.coml.org/), which has contributed to a significant increase in our knowledge of oceanic biodiversity, and seamounts were included in this decade long effort (Pitcher et al. 2007; http://censeam.niwa.co.nz/).

Seamounts are numerous, with perhaps 100000 existing throughout the world's oceans (Kinchingman et al. 2007). We argue in this paper for seamounts to be thought of as the underwater equivalent of oceanic islands, thus opening up the study of their biodiversity to the powerful theoretical developments in island biogeography. The patterns of abundances and the special adaptations of the fauna and flora of oceanic islands are of great interest to those who want to understand the origin of biodiversity and in particular endemism as a characteristic of the fauna of many of these islands (Whittaker \& Fernández-Palacios 2007, Grant \& Grant 2008, Price 2008). As seamounts share many characteristics such as in their volcanic origin and their degree of isolation with oceanic islands, they could also be sites for high levels of endemism, as was first proposed by Hubbs (1959). In this paper, we develop this hypothesis and make some preliminary test of it using data on benthic and reef based fish found along the Hawaiian-Emperor (H-E) seamount chain. Our analysis is preliminary and illustrative, as so little is known about the fish communities on seamounts, making definitive tests of ideas out of reach at present. The principle aim of the paper is to demon- 
strate and develop the rudiments of an approach to the study of seamount fish diversity, which could be a fruitful guide to future work.

\section{SEAMOUNTS AS UNDERWATER ISLANDS}

Many oceanic islands and seamounts share their origin in volcanic activity (Wessel 2007, Staudigel \& Clague 2010). In the case of many seamounts the volcano was just not big enough to push material above sea level. Other seamounts are the remnants of volcanic oceanic islands that have been destroyed by erosion (Price \& Clague 2002). Volcanoes that do not break the sea surface can still achieve a great height above the sea floor. The extrusion of all the extra material forming the seamount can lead to a period immediately after the eruption when the seamount sinks as the weight of the structure depresses the earth's crust (Price \& Clague 2002, Wessel 2007). The rapid period of sinking can last for about $1 \mathrm{Ma}$ (million yr before present) and can reduce the height of the seamount by 1000 to $1500 \mathrm{~m}$ (Price \& Clague, 2002). This gradual sinking is likely to be as important for speciation on seamounts as it is on islands. This sinking will often mean that there is a positive correlation between seamount peak depth and age.

Although seamounts extend from the seabed upwards, they do not offer a uniform habitat from top to bottom. This is of course also true of terrestrial islands, but their lower regions are sharply demarcated by the division between the terrestrial and marine habitats, each requiring very different adaptations for survival. This has obvious consequences for the biota in each habitat, setting sharp boundaries to distributions. Does a seamount have similarly sharp limits between any of its habitat zones? Marine organisms are just as limited by the physical conditions they can tolerate as are terrestrial plants and animals, and depth is one of the most overbearing abiotic factors affecting marine organisms, with physical conditions changing rapidly with depth (Mann \& Lazier 2006, Longhurst 2007). Do these physical conditions all change gradually with depth, or is there an equivalent to the land/sea boundary at some clearly demarcated depth? As Longhurst (2007) writes:

As biogeographers have long been aware, the most significant environmental gradient and discontinuity in the ocean is horizontal, between shallow and deep layers, rather than in the vertical plane [...]. This gradient lies at the seasonal or tropical pycnocline and is globally associated with the change from epipelagic to deeper ecosystems. (p. 43-44)

The depth of the pycnocline varies with latitude and in relation to landmasses (Longhurst 2007). Its depth is also dynamic through the year, being strongly influ- enced by varying insolation and wind-induced mixing. This sharp boundary at the pycnocline means that, for the purposes of this paper, we only consider seamounts with peaks that are $<500 \mathrm{~m}$ from the surface. At the bottom of this range, conditions will be closer to those in the deep ocean, but at shallower depths peaks will be in the euphotic zone and projecting through the pycnocline. These relatively shallow seamounts are most likely to have biodiversity that is high and dynamic.

Spatially the biota on these subsurface islands will be subject to the same factors that influence the biota on terrestrial islands in the sea. They will be separate from other islands and from continental shelves in the euphotic zone, and they will be exposed to immigration of organisms from these other locations. The degree of immigration will be a function of an organism's life history, and as many fish have pelagic eggs and larvae, they can be expected to have the potential to be dispersed widely. This needs to be taken into account when considering opportunities for the evolution of endemics. This problem is no different to birds and insects that can fly. As with degrading terrestrial islands, some of these seamounts will be expected to gradually sink as time passes so that eventually their tops pass below $500 \mathrm{~m}$ and out of the direct influence of surface events.

\section{THEORIES OF ISLAND BIOGEOGRAPHY AND THE STUDY OF SEAMOUNT BIODIVERSITY}

The first, and still the most cited, theory which attempts to explain the number of species found on islands is by MacArthur \& Wilson (1967). Their hypothesis was that the number of species on an island is determined by the balance between species arriving by immigration and species becoming extinct. Much research has been based on this theory, but Hubbell (2001) and, most recently, Whittaker et al. (2008) have modified and expanded the theory to account for processes and observations not included in the original. This paper is not the place for a full explanation of this new work, but a brief outline of Whittaker et al.'s (2008) theory is required to make the rest of the paper understandable.

The original theory of island biogeography (MacArthur \& Wilson 1967) did not develop in detail the evolution of species once they had arrived on an island. Evolution is part of Hubbell's (2001) theoretical development as well as of the theory proposed by Whittaker et al. (2008). The latter is tailored to the particular histories that will be experienced by an oceanic island which will exist for a limited period of time. As we are assuming that seamount islands will also last for a limited period of time, it might be expected that they too will be the scenes of specia- 
tion. Whittaker et al.'s (2008) theory of island biogeography is depicted in Fig. 1. This theory is called the General Dynamic Model, or GDM. As Fig. 1 shows, immigration and extinction are still the important inputs and outputs to and from the ecosystem, but as the island ages speciation rises to a peak and then decreases as biodiversity in general increases and there are fewer opportunities for new forms to evolve. This is because there are fewer available niches as previous adaptations have filled those niches most readily exploited. The GDM predicts that large remote islands will be dominated by evolutionary change more than those islands closer to a landmass source. Note that the carrying capacity of the island, labelled as $K$, increases to a peak and then falls as the island is reduced in height and area by erosion and subsidence. The same process is hypothesised to happen in seamounts, with those having peaks starting above $500 \mathrm{~m}$ gradually dropping out of the euphotic zone.

The GDM has random immigration and extinction events providing basic inputs to an island but then assumes that competition for resources can drive speciation. Animals or plants found as endemics on only one island are taken as a measure of evolutionary dynamics within an archipelago. It has been argued by Emerson \& Kolm $(2005 a, b)$ that there is an association between high species numbers on an island and a high

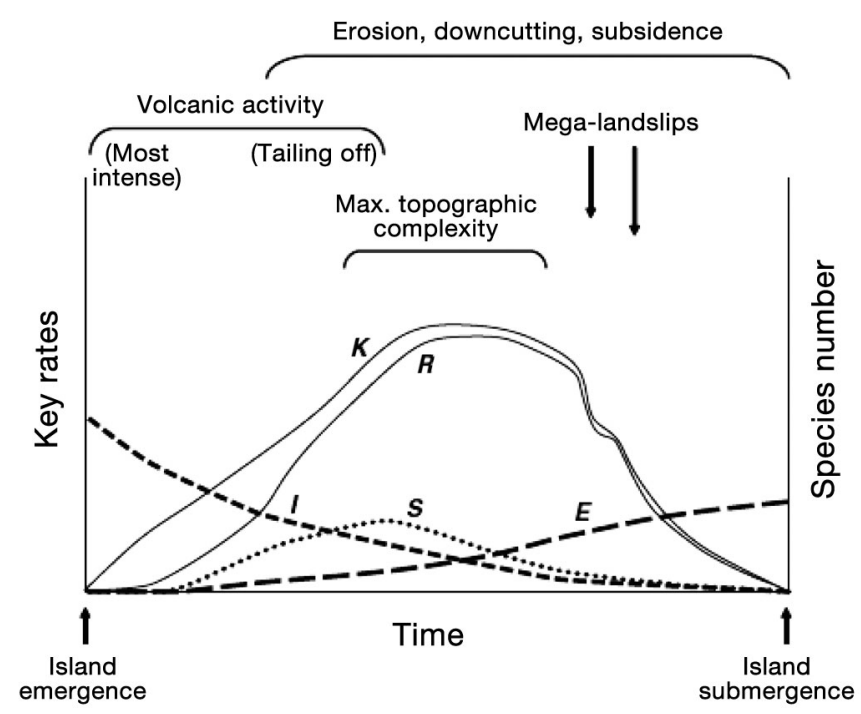

Fig. 1. General dynamic model as proposed by Whittaker et al. (2008). I and $E$ represent the immigration and extinction rates of species. $S$ is the rate of speciation, $K$ is the carrying capacity, and $R$ is the realised species richness resulting from a combination of immigration, speciation, and extinction. Unlike a terrestrial island, underwater seamount islands would reduce in height mainly through subsidence with little erosion. Undersea landslips could still be possible and there is evidence for these. (Figure from Whittaker et al. 2008) proportion of single island endemics. These authors argue that high diversity leads to increased competition for resources and to greater rates of speciation.

A number of predictions can be derived from the GDM (Whittaker et al. 2008), but several of them will be hard to test as the required data is difficult to obtain. We focus on just 3 predictions that are relatively easy to test. These are that: (1) The number of single seamount endemics (SSE) should be a humped function of seamount age. (2) Seamount (SM) species number should be a humped function of SM age. (3) This relationship between diversity and age will be improved by adding seamount area so that

$$
\text { Diversity }=a+b(\text { Age })+c\left(\text { Age }^{2}\right)+d(\log \text { Area })
$$

where $a, b, c$, and $d$ are fitted parameters.

The predictive power of the equation in prediction 3 is tested by Whittaker et al. (2008) against data sets on oceanic island fauna from the Canary Islands, Hawaii, USA, the Galápagos, the Marquesas and the Azores. Generally, diversity in the data sets used is well described by the regression.

Using data on benthic and reef-based fish from the H-E seamount chain, we show how the GDM might be used to analyse seamount biodiversity. Data from benthic and reef-based fish were used because fish in these groups are more likely to be dependent on a seamount and more likely to be non-migratory. Seamounts are attractive to many far-ranging species such as tuna and sharks, which gather at the good feeding opportunities offered by a seamount, but these are excluded from our analysis as they are unlikely to be seamount specific (Holland \& Grubbs 2007, Litvinov 2007, Morato et al. 2010). First we discuss briefly our current knowledge of diversity and endemism of seamount fish.

\section{DIVERSITY AND LEVELS OF ENDEMISM IN THE FISH COMMUNITIES OF SEAMOUNTS}

Levels of diversity and rates of endemism on seamounts have been reviewed by Stocks \& Hart (2007) and Shank (2010). At present, estimates of species diversity for any group are beset by problems derived from sampling. When attempting to compare seamount and continental margin diversity, the latter habitat will usually have been sampled with greater intensity than will the seamounts. Also, the gear used for data collection is more likely to sample the relatively smooth bottom of the shelf margin more effectively than it will the rough and rocky seamount. Seamounts are also under-sampled, as shown by plots of numbers of species collected against number of samples for 180 seamounts (Stocks \& Hart 2007). Such plots always 
produce a straight line for all seamounts sampled so far with no sign of the number of species reaching an asymptote. This implies that we still do not have good estimates of total species for any seamount.

The data on fish is not yet good enough to examine whether continental margins have more or less species that do seamounts. Equally, species evenness, which provides an indication of whether or not the community is dominated by a few species, cannot be estimated properly. The only indication we have that evenness might be low is the evidence from commercial fisheries on seamounts, which tend to be dominated by one or a few species.

Stocks \& Hart (2007) defined endemism as a species that is found on one seamount or a group of seamounts close together and nowhere else in the ocean. It is never possible to be sure that a species is endemic, especially as seamount sampling is so poor. There is always the chance that the apparently endemic species exists elsewhere but has just not yet been discovered. A check on FishBase (www.fishbase.org, last accessed July 5, 2010) will sometimes show that a species found on just one seamount has also been recorded elsewhere in the relevant ocean basin. In addition, because databases of seamount fish are compiled from a range of sources varying in age and the taxonomic precision of the providers, the problem of synonymy also arises. A species record from a seamount, which appears to be unique may be thought to be so because the data gatherers used an old name for a species. Again, a check on FishBase will first point to the synonym and then show that the species has been found in many other parts of the same ocean.

An early survey by Wilson \& Kaufmann (1987) found that $11.6 \%$ of 449 species of fish from 100 seamounts were endemic, but $72 \%$ of the data came from just 5 seamounts, so this survey is not definitive. Parin et al. (1997) found that $44 \%$ of 171 species of fish caught were endemic on the Nazca and Sala-y-Gómez chain of seamounts in the southeast Pacific. Richer de Forges et al. (2000) surveying the Norfolk Ridge, the Lord Howe seamounts, and the Tasmanian seamounts in the southwest Pacific found that 29 to $34 \%$ of all fishes caught were new or potentially endemic. The survey of seamount fishes by Froese \& Sampang (2004) estimated that only $12 \%$ of fish from 60 seamounts were endemic.

An expectation dependent on endemism is that fish that have evolved on just one seamount or a group of closely placed seamounts would be genetically different from fish that are closely related but on distant seamounts. Evidence reviewed by Stocks \& Hart (2007) shows no support for genetic separateness, although the small amount of data available does not make this a strong result.

\section{METHODS AND DATA SOURCES}

\section{Testing the GDM with data from the H-E seamount chain}

Over the past year and a half we have assembled a database of fish species recorded on seamounts. The data has been extracted from the web-based SeamountsOnline (seamounts.sdsc.edu, last accessed July 5, 2010) (Stocks 2010), from the Ocean Biogeographic Information System website (www.iobis.org/, last accessed July 5, 2010), the Earth Reference Data and Models site (www.earthref.org), from FishBase (www.fishbase.org, last accessed July 5, 2010), and from the Encyclopaedia of Life (www.eol.org, last accessed July 5, 2010). Our database contains 2138 records from all seamounts where fish have been recorded. Apart from species names we have also gathered information on the type of habitat in which the fish lives, the depth of the seamount peak and the total height of the seamount, its latitude and longitude, the distance to the next seamount, and the distance to the nearest continental shelf. Where possible we have also recorded the estimated age of the seamount.

The distribution of seamounts that have been sampled is patchy, and in many cases there is only a very small amount of data recorded from a particular place. To test the GDM, we need to be sure that we are using the most completely sampled set of seamounts; consequently, for the purposes of testing the theory we decided to focus on the H-E seamount chain, as the fish records from this chain make up $34 \%$ of all our data. The chain is also well-defined in time, and we know that even if estimated ages are inaccurate (see Baksi 2005), seamounts close to Hawaii will be the youngest ( 0.4 Ma) and those furthest from away will be the oldest ( 75.8 Ma) (Clouard \& Bonneville 2005). The estimated ages of H-E seamounts included in our analysis are shown in Table 1.

Most of the data on fish distributions along the H-E seamount chain comes from Uchida \& Uchiyama (1986). The data came from a survey of the chain lasting $5 \mathrm{yr}$ and organised by the Southwest Fisheries Center Honolulu Laboratory, National Marine Fisheries Service (NMFS). Data were gathered on 24 cruises and from 18 other commercial trips operating in the area of the northwest Hawaiian Islands but with no scientific observers on board. The vessels used midwater and bottom trawls, pole and lines, longlines, traps and handlines to catch fish. Bottom fish were mostly sampled with fish traps, lobster pots, shrimp pots, crab nets, dertical longlines, and handlines (Uchida \& Uchiyama 1986). No data on the amount of effort used to catch the fish is given in the report.

During the same period that the NMFS survey was carried out (1976-1981) the Soviet fishing fleet was removing large quantities of pelagic armourhead Pseudo- 
Table 1. The 20 seamounts and banks along the Hawaiian-Emperor (H-E) seamount chain used in the analysis of fish biodiversity. Cross Seamount is not on the main line of seamounts and is an anomaly. For many of the analyses it was removed as an outlier. SSR: Single seamount record: Ma: million yr before present

\begin{tabular}{|lccccc|}
\hline Seamount & $\begin{array}{c}\text { Estmated } \\
\text { age (Ma) }\end{array}$ & $\begin{array}{c}\text { No. of } \\
\text { benthic and } \\
\text { reef fish }\end{array}$ & $\begin{array}{c}\text { Depth } \\
\text { of peak } \\
(\mathrm{m})\end{array}$ & $\begin{array}{c}\text { Area } \\
\left(\mathrm{n} \mathrm{miles}{ }^{2}\right)\end{array}$ & SSRs \\
\hline Academician Berg & 34 & 7 & 500 & 102.12 & 0 \\
Bank 8 & 28 & 22 & 64 & 308.53 & 3 \\
Bank 9 & 20 & 5 & 115 & 147.8 & 2 \\
Brooks Banks & 12 & 21 & 51 & 143 & 8 \\
Colahan & 39 & 6 & 274 & 68.8 & 0 \\
Cross Seamount & 0.5 & 4 & 595 & 81.6 & 0 \\
Equator (Pacific) & 30 & 6 & 20 & 27.23 & 0 \\
Hancock (NW and SE) & 34 & 42 & 265 & 30.63 & 8 \\
Kimmei and Koko & 44 & 5 & 500 & 142.9 & 0 \\
Ladd & 30 & 26 & 64 & 340.4 & 4 \\
Lira & 50 & 1 & 500 & 190.6 & 0 \\
Middle Bank & 7 & 30 & 35 & 572.55 & 16 \\
Milwaukee Group & 45 & 16 & 20 & 424.4 & 0 \\
(Yuryaku and Kammu) & & & & & \\
Nero & 28 & 26 & 62 & 217.85 & 2 \\
Raita Bank & 27 & 14 & 16.4 & 2389 & 2 \\
Saint Rogatien Bank & 12 & 4 & 22 & 1838.16 & 0 \\
Salmon Bank & 27 & 17 & 55 & 925.09 & 2 \\
Turnif & 28 & 4 & 20 & 122.544 & 0 \\
Twin Banks & 2 & 12 & 20 & 1531.8 & 0 \\
Zapadnaya & 28 & 10 & 500 & 183.816 & 3 \\
\hline
\end{tabular}

dataset (Fig. 2). Each one of the 49 species is a putative endemic, but www.fishbase.org and the Encyclopaedia of Life (www.eol.org) were used to check synonyms and distributions. Using these sources, we found that of the 49 fish species found on only one seamount in our database, 41 are also found elsewhere in the Pacific. Of the remaining 8 species, only one is recorded from just one seamount whilst the others are endemic to the H-E seamount chain. The only putative single seamount endemic is Tosanoides filamentosus (Serranidae) found on the Hancock seamounts. As a result of this analysis we could not test whether the number of endemics has a humped relationship with seamount age as predicted by the GDM.

In the quest for factors that might predict the number of single seamount records (SSR) we plotted their number against the combined number of reef-associated and benthic species found on the associated sea-

pentaceros wheeleri and alfonsino Beryx splendens from the chain (Clark et al. 2007). This fishery would not only have removed these fish but would also have damaged habitats for reef-dwelling and benthic fish. There is no way that these removals can be factored into our data set, but should be borne in mind when evaluating the outcome of our analysis.

\section{Endemism on the H-E seamount chain}

Species recorded from only one seamount along the $\mathrm{H}-\mathrm{E}$ seamount chain are the largest group in our

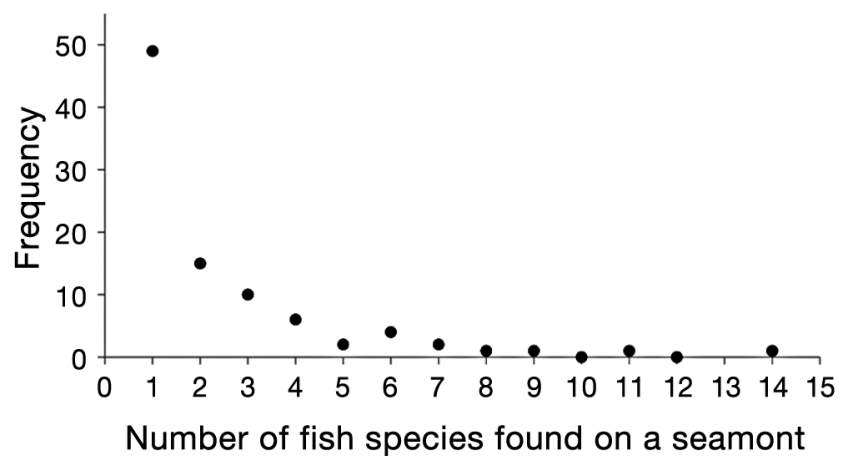

Fig. 2. Frequency of the number of fish species recorded from a seamount. The 49 species each recorded on only one seamount are potential endemics mount and the relationship is Number SSRs $=-1.25+$ 0.27 (Benthic + Reef fish). The model accounted for a $53 \%$ of the variation in SSR number, with $F=18.63$, p < $0.0005, \mathrm{df}=1,17$. A further factor in determining the number of SSRs could be the depth of the peak with deeper peaks being harder to sample adequately. The number of SSRs has a weak negative correlation with depth. Including this variable with the number of benthic and reef fish in a multiple regression with the number of benthic and reef-based fish resulted in the model accounting for $53 \%$ of the variation, with $F=$ 9.73, $\mathrm{p}=0.0015, \mathrm{df}=2,17$. Adding the additional variable does not increase significantly the amount of variance explained.

\section{Number of species on H-E seamount chain}

GDM predicts that the number of species on seamounts should be a humped function of age. To test this we plotted the number of species of reef and benthic fish against seamount age, and the relationship is shown in Fig. 3. There is considerable scatter in the data, but a fitted polynomial, constrained to pass through zero, shows that Diversity $=1.34$ Age -0.03 $\mathrm{Age}^{2}$. An analysis of variance shows that this fitted curve accounts for a significant proportion of the variance in diversity with $F=15.12$, df $=2,18$, and $\mathrm{p}=$ 0.0001 . 


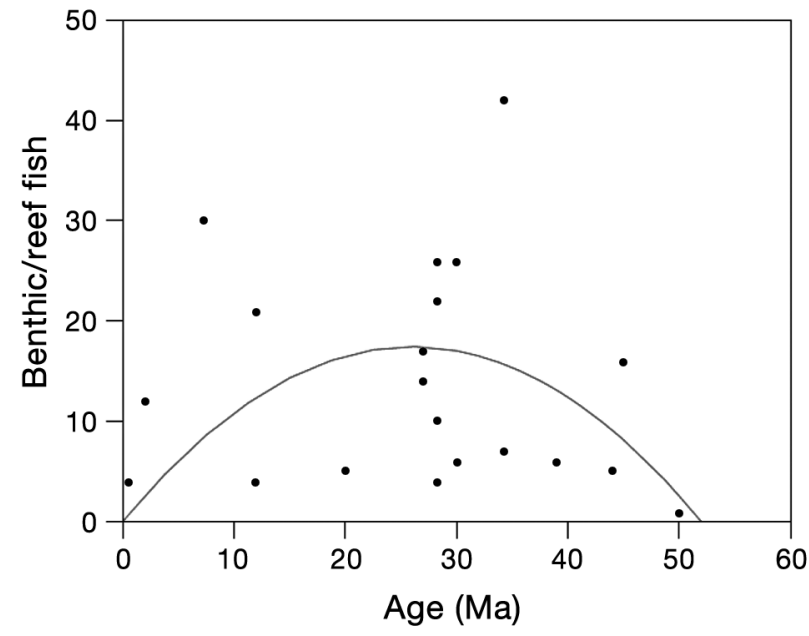

Fig. 3. Number of benthic and reef-dwelling fish found on seamounts and banks of the Hawaiian-Emperor (H-E) seamount chain plotted against the estimated age of the seamount. The line is a fitted polynomial with the origin constrained to pass through zero

\section{Number of species on $\mathrm{H}-\mathrm{E}$ seamounts is predicted by seamount area and age}

The GDM expands on the model from the previous section and includes seamount area as an additional explanatory variable so that $N=a+b($ Age $)+c\left(\right.$ Age $\left.^{2}\right)+$ $d(\log$ Area). Applied to the data on the number of reef and benthic fish recorded from the H-E seamount chain, the equation only accounts for $22 \%$ of the variance. An ANOVA shows that the model is not accounting for a significant portion of the variance, with $F=$ 1.38 , df $=3,15$, and $\mathrm{p}=0.29$.

\section{Looking for alternative predictors of species abundance on H-E seamounts}

The depth of the seamount peak is correlated with age, and there is a positive relationship between these 2 variables, so that Depth of peak $(\mathrm{m})=-71.54$ +8.50 Age (Ma), which explains $31 \%$ of the variance. An ANOVA shows that the model accounts for a significant amount of the variance, with $F=1.77$, $\mathrm{df}=1,17$, and $\mathrm{p}=0.01$. As older seamounts might be expected to have accumulated more species over time, it is possible that deeper and older seamounts have more species. A plot of the number of reef and benthic fish combined against seamount depth shows that the relationship is in fact negative and accounts for only $19 \%$ of the variance. An ANOVA shows that the model does not account for a significant amount of the variance, with $F=4.10, \mathrm{df}=1,17$, and $\mathrm{p}=$ 0.06 .

\section{DISCUSSION}

Although 49 species have only been recorded from one seamount on the H-E chain, further analysis showed that most of these have also been found elsewhere in the Pacific. The total number of species found on a seamount is positively correlated with the number of species found on only one seamount. This echoes the thesis of Emerson \& Kolm (2005a,b), who argue that high species numbers on an island accompany a high proportion of single island endemics. In this case the result obtained in the present study probably implies that the number of single seamount records is an artefact of the poor sampling rather than a reflection of the true rarity of species. Establishing endemism is always difficult but made harder on seamounts by the difficulties of sampling.

Data from other seamount chains reviewed by Stocks \& Hart (2007) implies that endemism could be significant, but even in the cases cited the paucity of sampling is still an important consideration.

Our analysis of the relationship between the number of benthic and reef fish and seamount age follows the prediction from the GDM. Seamounts of medium age will be expected to have the greatest number of niches and the highest carrying capacity. These factors lead to the expectation that speciation will lead to a greater number of species on seamounts of medium age. This confirmation of the GDMs prediction has to be interpreted with caution, given the nature of the data. With so few species in the data confined to just one or a few seamounts, the role of speciation in generating diversity is not well supported.

The prediction of the GDM that species abundance will be determined by seamount age and area, factors identified in the original MacArthur \& Wilson (1967) theory, is not supported by our analysis. Seamount age alone does bear a good relation with species abundance, but the addition of area renders the combined predictive effect non-significant. One factor to consider is that seamount area is hard to determine accurately from maps. We have measured area above the $500 \mathrm{~m}$ depth isocline. As with a mountain on an oceanic island, conditions change significantly as the seamount approaches the sea surface. This will mean that a seamount with a large area, most of which is between 500 and $300 \mathrm{~m}$ depth, will offer very different conditions to fish from seamounts with most of its area between 300 and $100 \mathrm{~m}$. The depth values we have are for the shallowest point, but this might just be a peak, with most of the habitable area on the seamount being at a much deeper depth. A more refined analysis of area is required before this aspect of the GDM can be tested properly. 
The connectivity of the H-E seamounts is an important issue for the analysis of endemics. As so many marine fish have planktonic larvae, the potential is high for distribution of species across several seamounts in an area. The main flow of water across the Hawaiian portion of the chain is from southwest to northeast (Uchida \& Uchiyama 1986), and this could mean that connectivity is not as good as might be expected. However, eddies are caused by the seamounts as the current flows through them, and this may retain larvae in the area and facilitate transfer from one seamount to the next (Lavelle \& Mohn 2010, Shank 2010). The evidence we reviewed on the wider distribution of the 49 species recorded from only one seamount showed that if they are to be found elsewhere in the Pacific it is usually to the west towards the Indonesian archipelago and the northeast coast of Australia (as shown on the Encyclopaedia of Life; www.eol.org). The Hawaiian seamounts are often the eastern-most location for many of these species. This ties in with the hypothesis proposed by Mora et al. (2003) that the Indonesian archipelago acts as a speciation hotspot, with fish dispersing from there to islands and reefs far and near, depending on the length of their larval phase.

The argument presented depends on the contention that within the sea there are boundaries at different depths that define the patterns of ecological and evolutionary processes. The chief boundary is between the euphotic and abyssal zones, essentially a boundary defining habitats with and without light. The lack of primary production in the abyssal zone defines a trophic regime, which is fundamentally different from the trophic opportunities that exist in the euphotic zone. As a result, one might expect different selection pressures to hold, and this is borne out by the very marked adaptations that deep sea fish have because they live in a food poor habitat (Marshall 1971). These differences mean that in any analysis of diversity on seamounts, depth must be a prime variable, but within a given depth zone, we are claiming that the same theory can be used to predict patterns of diversity. Within this depth zone, seamounts are equivalent to oceanic islands at the surface.

A further point to make is that studies of diversity need to take trophic level into account. The main theories of diversity on oceanic islands, particularly Hubbell's (2001) neutral theory, apply only to organisms at the same trophic level. The theory of Whittaker et al. (2008) is not specific about its trophic status, but as it proposes that competition on an increasingly populated island will lead to speciation, the theory implies that it only treats species living at the same trophic level.
The chief problem with any study of diversity and endemism on seamounts is the shortage of data and the difficulty inherent in obtaining it. Seamounts are often remote, and it is expensive to carry out surveys at the level of detail required. In addition, the sampling methods most often employed are non-selective and lacking in discrimination with respect to depth and precise habitat. Dredges and trawls just catch a collection of species from between 2 depths, but there is little chance of obtaining more spatially defined information on the species caught. Remote vehicles with cameras allow a more detailed survey of the spatial relations between organisms on a seamount, but such equipment is expensive and can only sample small areas at a time. We need good data from many seamounts within an oceanic region before it will be possible to determine whether or not seamounts are equivalent to oceanic islands in terms of their species diversity.

This paper has proposed a conceptual and theoretical framework within which the diversity of fish on seamounts can be analysed and discussed. Using data on benthic and reef fish found on seamounts belonging to the H-E seamount chain we have illustrated how the GDM of species diversity developed by Whittaker et al. (2008) could be used to analyse patterns and predict aspects of fish diversity. The thoughts expressed in this paper are just a start to the problem of understanding what the level of species diversity is on seamounts and whether seamounts are centres of speciation. The analysis presented is unsatisfactory because there is so little good data, making it impossible to test adequately the ideas proposed against the state of nature. From the point of view of conservation and management of seamount fish, we should be thinking in terms of closing all seamounts to exploitation until we understand their status more fully. At present we have only a weak scientific basis on which to plan conservation and management (Pitcher et al. 2007).

Acknowledgements. We thank Robert Whittaker for reading an early draft of the paper and making valuable suggestions for improvement.

\section{LITERATURE CITED}

Baksi AK (2005) Evaluation of radiometric ages pertaining to rocks hypothesized to have been derived by hotspot activity, in and around the Atlantic, Indian, and Pacific Oceans. Geol Soc Am Spec Pap 388:55-70

Clark MR, Vinnichenko VI, Gordon JDM, Beck-Bulat GZ, Kukharev NN, Kakora AF (2007) Large-scale distantwater trawl fisheries on seamounts. In: Pitcher TJ, Morato T, Hart PJB, Clark MR, Haggan N, Santos RS (eds) Seamounts: ecology, fisheries and conservation. Blackwell Publishing, Oxford, p 361-399

Clouard V, Bonneville A (2005) Ages of seamounts, islands 
and plateaus on the Pacific plate. In: Foulger GR, Natland JH, Presnall DC, Anderson DL (eds) Plates, plumes, and paradigms. Geol Soc Spec Pap 388. The Geological Society of America, Boulder, CO, p 71-90

Emerson BC, Kolm N (2005a) Species diversity can drive speciation. Nature 434:1015-1017

Emerson BC, Kolm N (2005b) Emerson and Kolm reply. Nature 438:E1-2

Froese R, Sampang A (2004) Taxonomy and biology of seamount fishes. In: Morato T, Pauly D (eds) Seamounts: biodiversity and fisheries. Fish Cent Res Rep 12. Fisheries Centre, University of British Columbia, Vancouver, p 25-32

Grant PR, Grant BS (2008) How and why species multiply. The radiation of Darwin's finches. Princeton University Press, Princeton, NJ

Holland KN, Grubbs RD (2007) Fish visitors to seamounts: tunas and billfish at seamounts. In: Pitcher TJ, Morato T, Hart PJB, Clark MR, Haggan N, Santos RS (eds) Seamounts: ecology, fisheries and conservation. Blackwell Publishing, Oxford, p 189-201

Hubbell SP (2001) The unified neutral theory of biodiversity and biogeography. Princeton University Press, Princeton, NJ

Hubbs CL (1959) Initial discoveries of fish faunas on seamounts and offshore banks in the eastern Pacific. Pac Sci 13:311-316

Kinchingman A, Lai S, Morato T, Pauly D (2007) How many seamounts are there and where are they located? In: Pitcher TJ, Morato T, Hart PJB, Clark MR, Haggan N, Santos RS (eds) Seamounts: ecology, fisheries and conservation. Blackwell Publishing, Oxford, p 26-40

Lavelle JW, Mohn C (2010) Motion, commotion, and biophysical connections at deep ocean seamounts. Oceanography (Wash DC) 23:90-103

Litvinov F (2007) Fish visitors to seamounts: aggregations of large pelagic sharks above seamounts. In: Pitcher TJ, Morato T, Hart PJB, Clark MR, Haggan N, Santos RS (eds) Seamounts: ecology, fisheries and conservation. Blackwell Publishing, Oxford, p 202-206

Longhurst A (2007) Ecological geography of the sea, 2nd edn. Academic Press, Amsterdam

MacArthur RH, Wilson EO (1967) The theory of island biogeography. Princeton University Press, Princeton, NJ

Mann KH, Lazier JRN (2006) Dynamics of marine ecosystems, 3rd edn. Blackwell Publishing, Oxford

Marshall NB (1971) Explorations in the life of fishes. Harvard University Press, Cambridge, MA

Mora C, Chittaro PM, Sale PF, Kritzer JP, Ludsin SA (2003) Patterns and processes in reef fish diversity. Nature 421: 933-936

Morato T, Hoyle SD, Allain V, Nicol SJ (2010) Seamounts are hotspots for pelagic biodiversity in the open ocean. Proc Natl Acad Sci USA 107:9707-9711

Submitted: May 23, 2010; Accepted: November 18, 2010
Parin NV, Mironov AN, Nesis KN (1997) Biology of the Nazca and Sala y Gómez submarine ridges, an outpost of the Indo-West Pacific fauna in the eastern Pacific Ocean: composition and distribution of the fauna, its communities and history. Adv Mar Biol 32:145-242

Pitcher TJ, Morato T, Hart PJB, Clark MR, Haggan N, Santos RS (2007) The depths of ignorance: an ecosystem evaluation framework for seamount ecology, fisheries and conservation. In: Pitcher TJ, Morato T, Hart PJB, Clark MR, Haggan N, Santos RS (eds) Seamounts: ecology, fisheries and conservation. Blackwell Publishing, Oxford, p 476-488

Pitcher TJ, Morato T, Hart PJB, Clark MR, Haggan N, Santos RS (eds) Seamounts: ecology, fisheries and conservation. Blackwell Publishing, Oxford

Price T (2008) Speciation in birds. Roberts and Co., Greenwood Village, CO

Price JP, Clague DA (2002) How old is the Hawaiian biota? Geology and phylogeny suggest recent divergence. Proc Biol Sci 269:2429-2435

Richer de Forges B, Koslow JA, Poore GCB (2000) Diversity and endemism of the benthic seamount fauna in the southwest Pacific. Nature 405:944-947

Shank TM (2010) Seamounts. Deep-ocean laboratories of faunal connectivity, evolution, and endemism. Oceanography (Wash DC) 23:108-122

Staudigel H, Clague DA (2010) The geological history of deep-sea volcanoes. Biosphere, hydrosphere and lithosphere interactions. Oceanography (Wash DC) 23:58-71

Stocks KI (2010) Box 10l SeamountsOnline: a desktop window into the lives of seamounts. Oceanography (Wash DC) 23:145

Stocks KI, Hart PJB (2007) Biogeography and biodiversity of seamounts. In: Pitcher TJ, Morato T, Hart PJB, Clark MR, Haggan N, Santos RS (eds) Seamounts: ecology, fisheries and conservation. Blackwell Publishing, Oxford, p 255-281

Uchida RN, Uchiyama JH (eds) (1986) Fishery atlas of the northwest Hawaiian Islands. NOAA Tech Rep NMFS 38:1-142

Wessel P (2007) Seamount characteristics. In: Pitcher TJ, Morato T, Hart PJB, Clark MR, Haggan N, Santos RS (eds) Seamounts: ecology, fisheries and conservation. Blackwell Publishing, Oxford, p 3-25

Whittaker RJ, Fernández-Palacios JM (2007) Island biogeography: ecology, evolution, and conservation, 2nd edn. Oxford University Press

Whittaker RJ, Triantis KA, Ladle RJ (2008) A general dynamic theory of oceanic island biogeography. J Biogeogr 35: 977-994

Wilson RR, Kaufmann RS (1987) Seamount biota and biogeography. In: Keating BH, Fryer P, Batiza R, Boehlert GW (eds) Am Geophys Union Geophys Monographs 43. American Geophysical Union, Washington, DC, p 355-378

Proofs received from author(s): February 1, 2011 